\title{
The specific outcomes of reactivation-induced memory changes depend on the degree of competition between old and new information
}

\author{
Almut Hupbach* \\ Lehigh University, Bethlehem, PA, USA \\ *Correspondence: hupbach@lehigh.edu
}

\section{A commentary on}

Does reconsolidation occur in humans?

by Schiller, D., and Phelps, E. A. (2011). Front Behav Neurosci 5: 24. doi: 10.3389/ fnbeh.2011.00024

Schiller and Phelps review the current state of knowledge on reconsolidation in human memory. Reconsolidation as a hypothetical memory re-stabilization process following memory reactivation is especially difficult to study in humans, because most pharmacological agents shown to impact reconsolidation in animals are not safe for human use. Thus, most human studies employ behavioral interference paradigms, i.e., after reactivating a memory (or not), potential interfering information is presented. Depending on the paradigm used (fear conditioning, procedural, or episodic memory tasks), new information either impairs the reactivated old memory, or the new information gets incorporated into the reactivated memory. For example, in procedural memory, the learning of a new finger-tapping sequence after reactivating a previously learned sequence impairs long-term memory of the first sequence (Walker et al., 2003). Similarly, in fear conditioning, extinction training that is administered 10 min after the reactivation of the fear memory leads to long-term extinction of the fear response (skin conductance response), while leaving the explicit knowledge of cueshock relationship unaltered (Schiller et al., 2010). And in episodic memory, learning a new set of objects after reactivating memory for a previously learned set leads to incorporation of new objects into memory for the old set (Hupbach et al., 2007).

Schiller and Phelps introduce an interesting explanation for the variable effects of post-reactivation interference treatments on subsequent memory performance. Their approach rests on the notion that the spe- cific type of memory alteration (impairment, extinction, incorporation of new information) is dependent upon the relative localization vs. distribution of the underlying memory representations. Fear conditioning and procedural memory are supported by rather localized brain systems (fear conditioning: basolateral amygdala, e.g., LeDoux, 2000; motor sequence learning: basal ganglia, e.g., Packard and Knowlton, 2002). In contrast, episodic memories depend on the interplay between the hippocampal proper and widespread neocortical areas (see, e.g., Dickerson and Eichenbaum, 2010, for a review). Schiller and Phelps propose the following principle: the more localized a representation, the more likely behavioral interference will cause memory impairment; whereas, the more distributed the underlying memory representations, the more likely will behavioral interference result in integration of the new information into the reactivated memory.

I suggest an alternative explanation of the different outcomes in the different paradigms used. I would like to argue that the reviewed studies do not only differ with respect to the relative localization vs. distribution of brain systems involved, but also with respect to how the potentially interfering material that is presented after reactivation relates to the content of the original memory that reactivation renders labile. More specifically, although all of the reviewed studies use behavioral interference paradigms, the studies differ in the degree with which the newly presented information competes with the previously encoded information. In fear conditioning, the new information ("no shock") is in direct competition with the previously learned contingency ("shock"), i.e., an organism cannot display both responses simultaneously (fear and no fear; although, interestingly, there is a dissociation between the physiological response and explicit knowledge of the contingency). In procedural memory, the new finger-tapping sequence involves movement of the same fingers, and thus, might interfere directly with the motor program established for the old sequence. Again, both sequences cannot be performed at the same time (although there is the possibility that new sequence elements intrude into the old sequence, but Walker et al., 2003 do not report whether the errors consist of such intrusions). Hence, in both the fear conditioning and the procedural memory paradigm, the new information negatively affects the old, reactivated memory (extinction or impairment). In contrast, in the episodic memory task used by Hupbach et al. $(2007,2009)$, the second set of objects that is learned after reactivation is conceptually unrelated to the previously learned set. Hence, the new set does not directly compete with the old set, and thus, does not impair memory for the old set directly. Rather, items of both sets can "coexist," and elements of the new memory can get incorporated into the old reactivated memory.

Staying within the framework of the reconsolidation account, the alternative view presented here emphasizes competition vs. integration of old and new information during re-storage, and not during retrieval, i.e., during response generation. It is assumed that the reactivated memory is altered, a view that has recently been criticized by proponents of computational models of episodic memory retrieval (e.g., Sederberg et al., 2011). Future studies are needed to address the not-so new question of whether (human) memories can indeed be modified, and whether the specific direction of alteration is dependent upon the brain systems involved and/or the specific relationship between the old and the new information.

\section{REFERENCES}

Dickerson, B. C., and Eichenbaum, H. (2010). The episodic memory system: neurocircuitry and disorders. Neuropsychopharmacology 35, 86-104. 
Hupbach, A., Gomez, R., Hardt, O., and Nadel, L. (2007). Reconsolidation of episodic memories: a subtle reminder triggers integration of new information. Learn. Mem. 14, 47-53.

Hupbach, A., Gomez, R., and Nadel, L. (2009). Episodic memory reconsolidation: updating or source confusion? Memory 17, 502-510.

LeDoux, J.E. (2000). Emotion circuits in the brain. Annu. Rev. Neuosci. 23, 155-184.

Packard, M. G., and Knowlton, B. J. (2002). Learning and memory functions of the basal ganglia. Annu. Rev. Neurosci. 25, 563-593.
Schiller, D., Monfils, M. H., Raio, C. M., Johnson, D. C. LeDoux, J. E., and Phelps, E. A. (2010). Preventing the return of fear in humans using reconsolidation update mechanisms. Nature 463, 49-53.

Sederberg, P. B., Gershman, S. J., Polyn, S., and Norman, K.A. (2011). Human memory reconsolidation can be explained using the temporal context model. Psychon. Bull. Rev. 18, 455-468.

Walker, M. P, Brakefield, T., Hobson, J. A., and Stickgold, R. (2003). Dissociable stages of human memory consolidation and reconsolidation. Nature 425, 616-620.
Received: 23 May 2011; accepted: 14 June 2011; published online: 23 June 2011.

Citation: Hupbach A (2011) The specific outcomes of reactivation-induced memory changes depend on the degree of competition between old and new information. Front. Behav. Neurosci. 5:33. doi: 10.3389/fnbeh.2011.00033

Copyright (C) 2011 Hupbach. This is an open-access article subject to a non-exclusive license between the authors and Frontiers Media SA, which permits use, distribution and reproduction in other forums, provided the original authors and source are credited and other Frontiers conditions are complied with. 